\title{
COMPRESSION BANDAGES OR STOCKINGS IN PHLEBOLYMPHOLOGY?
}

\author{
Hugo Partsch \\ Medical University of Vienna, Austria
}

\begin{abstract}
According to the classical therapeutic concept, compression stockings are primarily used in milder forms of chronic venous insufficiency and for long-term maintenance therapy for lymphedema, while compression bandages are applied in severe stages (e.g. in venous ulcers) and for the initial decongestion therapy in lymphedema. This concept is mainly supported by the different therapeutic pressure exerted by stockings and bandages. While stockings do not exceed a pressure range of $40-50 \mathrm{mmHg}$ in either body position, properly applied bandages start with a resting pressure of 50-60 $\mathrm{mmHg}$, which rises by an additional $20-40 \mathrm{mmHg}$ during standing or walking, depending on the stiffness of the material. The higher therapeutic pressure exerted by compression bandages explains their hemodynamic advantage, which has been demonstrated by experiments comparing the efficacy of stockings in improving the venous calf pump. In addition, in this review some practical aspects are underlined, and clinical evidence reported in the literature is discussed.
\end{abstract}

Key words: compression bandages, varicose veins, compression stocking, venous insufficiency.

\author{
REVIEW PAPER \\ Phlebological Review 2014; 22, 2: 41-44 \\ DOl: $10.5114 /$ pr.2014.48902
}

Submitted: 19.01 .2015

Accepted: 20.01.2015

\author{
ADDRESS FOR CORRESPONDENCE: \\ Hugo Partsch \\ Emeritus Professor of Dermatology \\ Medical University of Vienna \\ Steinhäusl 126 \\ A 3033 Altlengbach, Austria \\ e-mail: Hugo.Partsch@meduniwien.ac.at
}

\section{UNDERSTANDING THE MAIN DIFFERENCES BETWEEN STOCKINGS AND BANDAGES}

The use of compression bandages has a tradition of several centuries, while the first compression stockings were developed around 1850, after rubber had been invented. Then it took more than 100 years until compression stockings of different compression classes were introduced into clinical practice. Since then compression stockings have been increasingly used, mostly due to the fact that application of stockings - contrary to such an application of bandages - can be delegated to the patient. However, this self-application may be quite difficult, resulting in poor patient's compliance. Several studies have shown that only half of the patients wear their stockings, while others do not use recommended compression therapy, primarily because of problems with putting on compression stockings and also due to discomfort experienced when wearing compression hosiery $[1,2]$.

The highest pressure of custom-made stockings fitted to the patient's leg is around $40 \mathrm{mmHg}$, with only slightly higher pressure during standing and walking (Fig. 1A). Stockings characterized by even higher pressure would be very difficult to put on and would be poorly tolerated by the patient because of constrictive effects exerted by elastic material. However, properly worn stockings reduce leg edema, which in turn results in a drop of pressure exerted by compression hosiery. Therefore sometimes after such a reduction of edema a smaller stocking may be needed.

Due to elasticity of the material, compression stockings expand when the calf muscles contract during walk- ing. Therefore, during standing and walking, pressure under the stocking will increase moderately, depending on the stiffness of the material (Fig. 1A).

In contrast to the stockings, compression bandages should usually be applied by trained medical staff, with initial sub-bandage pressure of more than $40 \mathrm{mmHg}$ [3]. In a standing and walking patient this pressure under a stiff bandage will rise to $70-100 \mathrm{mmHg}$, thereby adjusting to higher hydrostatic intravenous pressure (Fig. 1B). During muscle contractions during walking, bandages do not expand as compression stockings do, if they are made of stiff material. Thus, a much stronger massaging effect is observed (Fig. 1B). In addition, by combining different types of bandages applied in several layers, not only the initial pressure, but also stiffness is much higher compared to a stocking. Also, such multilayer bandages are well tolerated during rest and at night in spite of much higher pressures. Usually the bandages can stay on the leg overnight, which is not the case with compression stockings. Still, the bandages need to be changed when they become loose, which usually happens every 2-3 days at the beginning of the treatment, and later every 7 days.

\section{HEMODYNAMIC EFFECTS}

In a walking patient, properly applied compression bandages are more effective in terms of improving venous hemodynamics, due to much higher sub-bandage pressure, especially during muscle contractions. Consequently, the superficial and deep veins are intermittently 

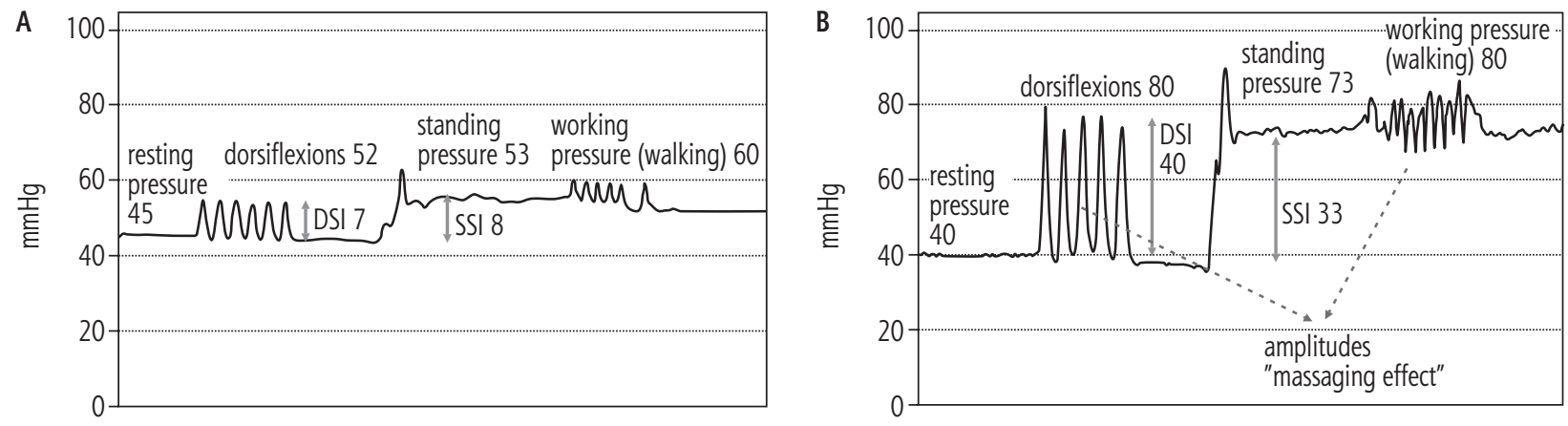

Fig. 1. Registration of interface pressure by positioning an air-filled transducer (Picopress) at the B1 point (transition of the muscular part of the medial gastrocnemius muscle into its tendon $(\sim 12 \mathrm{~cm}$ above the inner malleolus) in the lying position, during dorsiflexion, after standing up and during walking on the spot: A) under a double compression stocking ("ulcer kit"); B) under an inelastic bandage applied with a resting pressure of $40 \mathrm{mmHg}$. In spite of a comparable resting pressure of both devices, the dynamic stiffness index (DSI), the static stiffness index (SSI) and the pressure amplitudes during movement ("massaging effect") are much higher under the inelastic bandage compared to the stocking (DSI = peak pressure-resting pressure, SSI = standing-lying pressure)

compressed during every step. This phenomenon can be demonstrated by Duplex sonography and by MR imaging $[4,5]$. Also, an increase of the ejection fraction of the venous pump [6] and a decrease of ambulatory venous hypertension are observed [7]. In addition, the massaging effect on the microcirculation results in release of vasoactive, anti-inflammatory and anticoagulatory mediators from the endothelial cells [8]. In contrast to bandages, the main clinical effect of compression stockings is edema reduction, while the venous outflow from the leg is not much changed.

\section{CLINICAL INDICATIONS}

Since the bandages are more effective in term of hemodynamics, they are preferentially used in more severe cases of venolymphatic disease, while the stockings are primarily recommended in such patients during maintenance management of edema initially improved by bandages, and also in patients with milder venous and lymphatic disorders $[9,10]$. For example, patients with venous ulcers, and also those with severe lymphedema, should be managed with compression bandages until the ulcers are healed or no further reduction of lymphedema is seen. This concept, based on the results of randomized clinical trials (RCT), is endorsed by several guidelines [9-14].

\section{RANDOMIZED CLINICAL TRIALS}

A number of RCTs have confirmed the clinical efficacy of mild compression stockings, with a pressure less than $20 \mathrm{mmHg}$, for improving subjective complaints in patients with subjective symptoms but no signs of venous disorders (CEAP C0s) or with spider veins and symptoms (CEAP C1s) and in pregnant women with varicose veins. Also such efficacy has been shown concerning the prevention of leg swelling related to prolonged sitting and standing, the so-called occupational leg edema, and for the prevention of venous thromboembolism in bed-ridden patients, especially after surgery [10]. Low-pressure stockings have no, or only doubtful clinical benefit following varicose vein surgery. Medical compression stockings (MCS) with a pressure range of $20-30 \mathrm{mmHg}$ produce beneficial clinical effects, after sclerotherapy of small telangiectasias, concerning an improvement of subjective symptoms in varicose veins in pregnant women and for the treatment of acute deep vein thrombosis [10]. Medical compression stockings with a pressure range between 30 and $40 \mathrm{mmHg}$ can be recommended after sclerotherapy, in patients with lipodermatosclerosis (CEAP C4b) and those with small venous ulcers. Several RCTs have demonstrated that the rate of postthrombotic syndrome after proximal deep vein thrombosis (DVT) can be reduced by wearing compression stockings with a pressure of 30$40 \mathrm{mmHg}$ [10]. Yet, a very much debated study has recently questioned the value of routinely wearing compression hosiery after acute DVT [15].

Several studies have shown positive healing effects of compression stockings particularly in selected patients with small and not long lasting venous leg ulcers [16], especially when compared with inadequately applied bandages [17].

For the use of compression bandages strong recommendations can be given in patients with venous ulcers (CEAP C6) [11-13] and for management of lymphedema $[9,18]$.

In the field of venous ulceration an extensive Cochrane review [11] and a recent recommendation from the American Venous Forum [12], together with a meta-analysis from the Mayo Clinic [13], emphasized that compression bandages are the mainstay of conserv- 
ative therapy of venous leg ulcers. A randomized controlled trial from Hong Kong, which has changed the conventional concept of leg ulcer treatment in that area, showed a healing rate that was more than twice as high with bandages compared to the usual local ulcer treatment without compression. Inelastic bandages were more effective than four-layer bandages [19].

Comparing the pressure levels achieved by different compression devices, there is some evidence that those of higher pressure produce better healing rates than lower-pressure devices [20,21].

\section{SOME PRACTICAL CONSIDERATIONS}

For many, especially elderly patients, it is a "torture" to put on compression stockings every morning and to take them off in the evening, which leads to poor compliance. In some regions home-nurses are organized to do this, which is however a very expensive modality. The so-called ulcer kits, consisting of two stockings, which are applied one over the other, facilitate the handling.

Proper application of stiff bandages, which stay on the leg for several days and nights, is more effective, especially in large and long standing ulcers, and shows better compliance, which is under the control of the person applying these compression devices. Ulcer patients treated with good bandages experience an immediate improvement of pain, reduction of edema and decreased secretion of exudate. They acquire confidence in the effectiveness of compression therapy and are ready to continue compression with the stockings when the ulcers are healed.

\section{WHICH ARE THE PROPER COMPRESSION BANDAGES?}

The main prerequisites of a proper bandage are good tolerability in the lying position ("low resting pressure") and high working pressure during walking. These prerequisites are fulfilled by using stiff bandages consisting of several layers of inelastic textiles. Stiffness can also be achieved by using cohesive or adhesive surfaces. Also, adding more layers of elastic material over each other may produce a rather stiff product, due to the increased friction between the layers, but such bandages may be poorly tolerated due to the constrictive effect of the elastic material.

If stiff bandages are applied with sufficient initial pressure (Fig. 1B), they may be called "intelligent bandages", because their pressure will increase when the calf muscle contracts during each step, which causes a massaging effect on the leg and intermittent narrowing of the veins, leading to increase of the ejection fraction of the venous pump and to reduction of ambulatory venous hypertension in patients with chronic venous insufficiency. Modern textiles contain more than $90 \%$ cotton and can be washed and re-used, even longer than the lifetime of compression stockings. This makes the use of such bandages much cheaper than the management with compression stockings. One important precondition for using inelastic bandages is that medical professionals putting on the bandages should be trained to achieve adequate initial pressure ranges, as shown in Fig. 1B. A recent study from Denmark concluded that the majority of bandages in the community are applied too loosely, and that therefore training programs focusing on practical bandaging skills should be implemented to improve management of venous leg ulcers [22]. Stiff compression devices, which can be handled by the patients themselves, are adjustable Velcro-band devices, which may offer an alternative treatment modality in the future. The application of inelastic bandages with an initially higher pressure takes into consideration that the pressure drops immediately, since leg edema is very quickly reduced. However, it could be demonstrated that even after one week the improvement of the venous calf pump function is still higher under the bandage in comparison to compression stockings [23].

Of note, inelastic bandages applied using reduced pressure (up to $40 \mathrm{mmHg}$ ) can also be used to treat mixed arterio-venous ulcers in the legs with the ankle brachial blood pressure index (ABPI) of $>0.5$ or an absolute ankle pressure of $>60 \mathrm{mmHg}$ [24].

\section{CONCLUSIONS}

Compression bandages are not old fashioned and cannot be replaced by compression stockings. Exerting much higher pressures when correctly applied, inelastic bandages are hemodynamically more effective and should be the preferred treatment for the initial management of leg ulcers and lymphedema.

The author declares no conflict of interest.

\section{References}

1. Raju S., Hollis K., Neglen P. Use of compression stockings in chronic venous disease: patient compliance and efficacy. Ann Vasc Surg 2007; 21: 790-795.

2. Rabe E., Hertel S., Bock E., Hoffmann B., Jöckel K.H., Pannier F. Therapy with compression stockings in Germany - results from the Bonn Vein Studies. J Dtsch Dermatol Ges 2013; 11: 257-261.

3. Partsch H., Clark M., Mosti G., Steinlechner E., Schuren J., Abel M., Benigni J.P., Coleridge-Smith P., Cornu-Thénard A., Flour M., Hutchinson J., Gamble J., Issberner K., Juenger M., Moffatt C., Neumann H.A., Rabe E., Uhl J.F., Zimmet S. Classification of compression bandages: practical aspects. Dermatol Surg 2008; 34: 600-609.

4. Partsch B., Partsch H. Calf compression pressure required to achieve venous closure from supine to standing positions. J Vasc Surg 2005; 42: 734-738.

5. Partsch H., Mosti G., Mosti F. Narrowing of leg veins under compression demonstrated by magnetic resonance imaging (MRI). Int Angiol 2010; 29: 408-410. 
6. Mosti G., Mattaliano V., Partsch H. Inelastic compression increases venous ejection fraction more than elastic bandages in patients with superficial venous reflux. Phlebology 2008; 23: 287-294.

7. Partsch $\mathrm{H}$. Improving the venous pumping function in chronic venous insufficiency by compression as dependent on pressure and material. Vasa 1984; 13: 58-64.

8. Delos Reyes A.P., Partsch H., Mosti G., Obi A., Lurie F. Report from the 2013 meeting of the International Compression Club on advances and challenges of compression therapy. J Vasc Surg Ven Lymph Dis 2014; 2: 469-476.

9. Badger C., Preston N., Seers K., Mortimer P. Physical therapies for reducing and controlling lymphoedema of the limbs. Cochrane Database Syst Rev 2004; (4): CD003141.

10. Partsch H., Flour M., Smith P.C.; International Compression Club. Indications for compression therapy in venous and lymphatic disease consensus based on experimental data and scientific evidence. Under the auspices of the IUP. Int Angiol 2008; 27: 193-219.

11. O'Meara S., Cullum N., Nelson E.A., Dumville J.C. Compression for venous leg ulcers. Cochrane Database Syst Rev 2012; 11: CD000265.

12. O’Donnell T.F. Jr, Passman M.A., Marston W.A., Ennis W.J., Dalsing M., Kistner R.L., Lurie F., Henke P.K., Gloviczki M.L., Eklöf B.G., Stoughton J., Raju S., Shortell C.K., Raffetto J.D., Partsch H., Pounds L.C., Cummings M.E., Gillespie D.L., McLafferty R.B., Murad M.H., Wakefield T.W., Gloviczki P.; Society for Vascular Surgery; American Venous Forum. Management of venous leg ulcers: clinical practice guidelines of the Society for Vascular Surgery ${ }^{\circledR}$ and the American Venous Forum. J Vasc Surg 2014; 60 (2 Suppl): 3S-59S.

13. Mauck K.F., Asi N., Elraiyah T.A., Undavalli C., Nabhan M., Altayar O., Sonbol M.B., Prokop L.J., Murad M.H. Comparative systematic review and meta-analysis of compression modalities for the promotion of venous ulcer healing and reducing ulcer recurrence. J Vasc Surg 2014; 60 (2 Suppl): 71S-90S.e1-2.

14. Rybak Z., Franks P.J., Krasowski G., Kalemba J., Glinka M. Strategy for the treatment of chronic leg wounds: a new model in Poland. Int Angiol 2012; 31: 550-556.

15. Kahn S.R., Shapiro S., Wells P.S., Rodger M.A., Kovacs M.J., Anderson D.R., Tagalakis V., Houweling A.H., Ducruet T., Holcroft C., Johri M., Solymoss S., Miron M.J., Yeo E., Smith R., Schulman S., Kassis J., Kearon C., Chagnon I., Wong T., Demers C., Hanmiah R., Kaatz S., Selby R., Rathbun S., Desmarais S., Opatrny L., Ortel T.L., Ginsberg J.S.; SOX trial investigators. Compression stockings to prevent post-thrombotic syndrome: a randomised placebo-controlled trial. Lancet 2014; 383: 880-888.

16. Ashby R.L., Gabe R., Ali S., Adderley U., Bland J.M., Cullum N.A., Dumville J.C., Iglesias C.P., Kangombe A.R., Soares M.O., Stubbs N.C., Torgerson D.J. Clinical and cost-effectiveness of compression hosiery versus compression bandages in treatment of venous leg ulcers (Venous leg Ulcer Study IV, VenUS IV): a randomised controlled trial. Lancet 2014; 383: 871-879.

17. Partsch H., Horakova M.A. Compression stockings in treatment of lower leg venous ulcer. Wien Med Wochenschr 1994; 144: 242-249.

18. Lee B.B., Andrade M., Antignani P.L., Boccardo F., Bunke N., Campisi C., Damstra R., Flour M., Forner-Cordero I., Gloviczki P., Laredo J., Partsch H., Piller N., Michelini S., Mortimer P., Rabe E., Rockson S., Scuderi A., Szolnoky G., Villavicencio J.L.; International Union of Phlebology. Diagnosis and treatment of primary lymphedema. Consensus document of the International Union of Phlebology (IUP)-2013. Int Angiol 2013; 32: 541-574.
19. Wong I.K., Andriessen A., Charles H.E., Thompson D., Lee D.T., So W.K., Abel M. Randomized controlled trial comparing treatment outcome of two compression bandaging systems and standard care without compression in patients with venous leg ulcers. J Eur Acad Dermatol Venereol 2012; 26: 102-110.

20. Milic D.J., Zivic S.S., Bogdanovic D.C., Jovanovic M.M., Jankovic R.J., Milosevic Z.D., Stamenkovic D.M., Trenkic M.S. The influence of different sub-bandage pressure values on venous leg ulcers healing when treated with compression therapy. J Vasc Surg 2010; 51: 655-661.

21. Dolibog P., Franek A., Taradaj J., Dolibog P., Blaszczak E., Polak A., Brzezinska-Wcislo L., Hrycek A., Urbanek T., Ziaja J., Kolanko M. A comparative clinical study on five types of compression therapy in patients with venous leg ulcers. Int J Med Sci 2013; 11: 34-43.

22. Zarchi K., Jemec G.B. Delivery of compression therapy for venous leg ulcers. JAMA Dermatol 2014; 150: 730-736.

23. Mosti G., Partsch H. Inelastic bandages maintain their hemodynamic effectiveness over time despite significant pressure loss. J Vasc Surg 2010; 52: 925-931.

24. Mosti G., Iabichella M.L., Partsch H. Compression therapy in mixed ulcers increases venous output and arterial perfusion. J Vasc Surg 2012; 55: 122-128. 